\title{
ARTICLES
}

\section{EFFECTIVENESS OF STRUCTURED TEACHING PROGRAM REGARDING KNOWLEDGE ABOUT PERSONAL HYEGINE AMONG PRIMARY SCHOOL CHILDREN IN SELECTED SCHOOLS, BAHINDA}

\author{
Ms. Manpreet Kaur
}

Associate Professor, CON, Adesh University, Bathinda, Punjab, India. DOI: http://doi.org/10.47211/idcij.2020.v07i03.005

Received $24^{\text {th }}$ May 2020, Accepted $5^{\text {th }}$ June 2020, Available online $10^{\text {th }}$ July 2020.

\begin{abstract}
:
"The child power" for spreading health messages prof. Hugh hawker stales that "Children have a vitally important part to play in the health of community, nor merely by being 'kept healthy' by adult but in passing an health messages to younger brothers and sisters and by jointly co-operating to become a positive force of health child to child program is based on the concept that children in school and family members need to be considered as partners in spreading health messages as well as benefiting from them. The conceptual framework of the study was based on open system model Ludwig von Bertalanffy 1968. A quasi experimental approach was adopted for the study convenient sampling was used and 40 samples were selected. Demographic Performa was used to obtain background information of under five children mothers. According to frequency and percentage distribution of mean pre and post-test knowledge scores it has been depicted that, in experimental group (1) majority 14(70\%) participants had average knowledge, 3(15\%) participants had fair knowledge and 3(15\%) participants had poor knowledge and none of the participants had excellent and good knowledge. In experimental group (2) majority 12(60\%) had good knowledge, 4(20\%) participants had fair knowledge and 4(20\%) participants had excellent knowledge none of participants had poor or average knowledge
\end{abstract}

\section{KEY WORDS:}

Effectiveness, Structured teaching program, Knowledge, Personal hygiene and primary school children.

ABOUT AUTHOR:

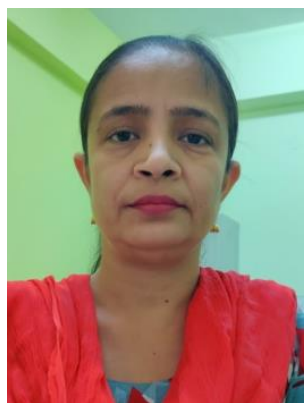

Author Ms. Manpreet Kaur is Associate Professor, CON, Adesh University, Bathinda, Punjab, India. 


\section{INTRODUCTION}

The present study was conducted to assess the effectiveness of structured teaching program on knowledge regarding personal hygiene among primary school children at slum area of district Bathinda, India adopted the National policy of children in August 1974 and recognized children as the "Nations supremely important asset". It was David Morley and his colleagues at the Institute of child health and education, university of London who identified the un-trapped resource. "The child power" for spreading health messages prof. Hugh hawker stales that "Children have a vitally important part to play in the health of community, nor merely by being ' kept healthy' by adult but in passing an health messages to younger brothers and sisters and by jointly co-operating to become a positive force of health child to child program is based on the concept that children in school and family members need to be considered as partners in spreading health messages as well as benefiting from them.

\section{OBJECTIVES}

- To assess the pre-test knowledge regarding personal hygiene among primary school children.

- To assess the post-test knowledge regarding personal hygiene among primary school children.

- To assess the effectiveness of structured teaching program regarding personal hygiene among primary school children.

- To determine the association between knowledge and selected demographical variables of primary school children.

\section{METHODOLOGY}

The conceptual framework of the study was based on open system model Ludwig von Bertalanffy 1968. A quasi experimental approach was adopted for the study convenient sampling was used and 40 samples were selected. Demographic Performa was used to obtain background information of under five children mothers. The self-structured knowledge questionnaire was used to assess the knowledge personal hygiene. Descriptive and inferential statistics was used to analyze the data. Frequency and percentage, Chi square and paired t test were used for the analysis.

\section{RESULTS}

- In control group, majority $10(50 \%)$ participants were boys and $10(50 \%)$ were girls and in experimental group $12(60 \%)$ participants were girls.

- Maximum 20, 18 in experimental group (90\%), respondents were of age group 9-11.

- In control group, majority $12(60 \%)$ subjects and in experimental group all $14(70 \%)$ subjects were from urban area.

- In control group maximum 9(45\%) participants belonged to +2 and in experimental group $9(45 \%)$ participants belonged to Graduation.

- In control group majority 6(30\%) belonged to graduation and in experimental group 6(30\%) subjects belonged to illiterate.

- In control group majority $8(40 \%)$ respondents belonged to Labor and in experimental group $8(40 \%)$ respondents belonged to Business.

- In control group maximum 9(45\%) belonged to house wives and in experimental group $9(45 \%)$ participants belonged to business.

According to frequency and percentage distribution of mean pre and post-test knowledge scores it has been depicted that, in experimental group (1) majority 14(70\%) participants had average knowledge, 3(15\%) participants had fair knowledge and 3(15\%) participants had poor knowledge and none of the participants had excellent and good knowledge. In experimental group (2) majority $12(60 \%)$ had good knowledge, 4(20\%) participants had fair knowledge and $4(20 \%)$ participants had excellent knowledge none of participants had poor or average knowledge.

\section{RECOMMENDATIONS}

Based on the experience gained during the period of study and from the result of the study, these recommendations were made

- The study can be replicated on large sample to validate and generalize its findings

- Similar study can be conducted in different settings like in Schools and community.

- An experimental study can conducted to find out the effectiveness of structured teaching program regarding personal hygiene among primary school children. 


\section{REFERENCES:}

1. Wong's, Essentials of pediatric Nursing. 6th edition 2002 published by Harcourt India Private limited, page No.512.

2. KasturiSundarRao, An Introduction to community health nursing. 2000. published by K.V.Mathew for B.I. publication page No : 214, 219, 220.

3. B.T. Basvanthappa, Community health nursing. 1998 published by Jaypee brothers page No.536.20 .

4. Maysa Haw Wash, Enabling education Network child to child approach to promote Inclusive education. www.eenet.org.uk/resource/docs/present.php www.who.org, Feb report 2004.

5. Gupta.M. Gupta.B.P.,Chauhan.A. Ocular 2009 morbidity prevalence among school children in Shimla, Himachal, North India, Community Eye care year. volume 7. issue 2. page No : 133-138.

6. Mishra.G., Indian Journal of community medicine, volume 31. No: 4 October - December 2006.

7. P.R. Walvekar 2006, Indian Journal community medicine volume 31. No: 2 2006-04 - 2006-06.

8. Christine Scotchiner. Executive Secretary. The child to child trust Institute of Education University.London publishers May \& Oct. 1996.

9. Pandey(s), Dudani I, Pradhan.A. Kattmandu 2005.U Health profile of school children in Bhaktapur.University medical journal vol. 3. No: 3. issue: 11, 274-280. 